\title{
Prepulse Inhibition Deficits in GAD65 Knockout Mice and the Effect of Antipsychotic Treatment
}

\author{
Scott A Heldt*,', Amanda Green' and Kerry J Ressler' \\ 'Center for Behavioral Neuroscience, Department of Psychiatry and Behavioral Sciences, Emony University, Atlanta, GA, USA
}

\begin{abstract}
Recent postmortem studies in humans suggest that defects in GABAergic neurotransmission might contribute to the neuropathology associated with schizophrenia. Disturbances in GABAergic systems may also contribute to the sensorimotor gating deficits classically observed in schizophrenic patients, including deficits in prepulse inhibition (PPI). To explore the relationship, the current study examined the integrity of PPI and startle habituation in knockout (KO) mice that lack the GABA synthesizing enzyme glutamic acid decarboxylase 65 (GAD 65). GAD65 KO mice displayed normal baseline and habituated startle responses, which did not differ from GAD65 wild-type (WT) or heterozygous (HET) mice. However, GAD65 KO mice showed robust deficits in PPI which were reversed by the atypical antipsychotic agent clozapine. These results lend support to the view that abnormalities in GABAergic systems might contribute to the basic pathophysiological mechanisms in schizophrenia.

Neuropsychopharmacology (2004) 29, 1610-1619, advance online publication, 28 April 2004; doi: 10.1038/sj.npp.1300468
\end{abstract}

Keywords: PPI; habituation; startle; glutamic acid decarboxylase; GAD; clozapine

\section{INTRODUCTION}

A deficiency in sensorimotor gating mechanisms is seen in a number of neuropsychiatric disorders including schizophrenia, Huntington's disease, obsessive-compulsive disorder, attention-deficit disorder, and Tourette's syndrome (for a review, see Braff et al, 2001). In humans and animals, the integrity of sensorimotor gating mechanisms is often measured by prepulse inhibition (PPI), which is the suppression of the startle reflex when a startling stimulus is preceded by a weak stimulus at lead times of $20-500 \mathrm{~ms}$. Over the past decade, studies using neuroanatomical, pharmacological, and genetic manipulations in animals have been useful in elucidating the neural circuitry underlying PPI. These findings have also been useful in providing insight into the pathophysiology of several forms of mental illness characterized by a disruption of sensorimotor gating.

Given the multitude of evidence suggesting that the pathophysiology of schizophrenia involves dysfunctions in dopaminergic, serotonergic, and glutamatergic neurotransmitter systems, it is no surprise that manipulations of these systems have been the primary focus in animal models of PPI (for a review, see Geyer et al, 2001). However, postmortem studies have also provided evidence for

* Correspondence: Dr SA Heldt, Yerkes Primate Research Center, Emory University, Atlanta, GA 30329, USA, Tel: +I 404727 739, Fax: + 404727 8070, E-mail: sheldt@emory.edu

Received I February 2004; revised 17 March 2004; accepted 18 March 2004

Online publication: 22 March 2004 at http://www.acnp.org/citations/ Npp03240404043/default.pdf abnormalities of the $\gamma$-aminobutyric acid (GABA)-ergic system in schizophrenia. For example, several independent laboratories have found reductions in the density and number of GABAergic interneurons of schizophrenic patients (Beasley et al, 2002; Benes et al, 1991; Kalus et al, 2002). Research groups have also reported significant reductions in levels of glutamic acid decarboxylase (GAD), which plays a central role in the synthesis and release of GABA (Akbarian et al, 1995; Guidotti et al, 2000; Hashimoto et al, 2003; Heckers et al, 2002; Impagnatiello et al, 1998; Volk and Lewis, 2002). Despite these primarily descriptive lines of evidence, at present, the precise nature of the link between GABAergic systems and schizophrenic symptomatology remains unclear. Thus, direct studies of the relationship between altered GABAergic systems and PPI may be valuable in the search to understand neuropsychiatric disorders characterized by the disturbances of sensorimotor gating.

GABA is the principal inhibitory neurotransmitter in the mammalian central nervous system and is synthesized by two isoforms of GAD, GAD65 and GAD67. The level of expression of each GAD isoform is heterogeneous at both regional and cellular levels; however, the functions of the individual isoforms are poorly understood (Sheikh et al, 1999; Soghomonian and Martin, 1998). In mice, the availability of both isoforms is necessary for normal development. GAD67 knockout (KO) mice show a marked reduction of GABA levels throughout the brain and die shortly after birth due to the development of a cleft palate (Asada et al, 1997). GAD65 KO mice appear healthy and exhibit no obvious morphological abnormalities (Asada 
et al, 1996). However, the lack of GAD65 during postnatal development leads to alterations in GABAergic transmission in later adulthood (Stork et al, 2000).

Schizophrenic patients show a deficit in normal PPI and startle habituation (eg Bolino et al, 1992; Braff et al, 1978; Braff et al, 1992; Ludewig et al, 2003). Since disturbances in GABAergic transmission may contribute to these deficits in schizophrenic patients, we set out to examine the integrity of PPI and startle habituation in GAD65 mice. In addition, we examined whether observed deficits could be reversed by the antipsychotic agent clozapine.

\section{MATERIAL AND METHODS}

\section{Animals}

Mice with genetic deletion of the GAD65 gene maintained on a mixed $129 / \mathrm{SvJ} \times \mathrm{C} 57 \mathrm{BL} / 6$ genetic background were originally generated by Kash et al (1997). Heterozygous breeding pairs were obtained from Jackson Laboratories (C57BL/6J-Gad2, Stock\# 003654; Bar Harbor, ME) and bred to produce an F1 population. Owing to the potential confounds of maternal behavior in genetic studies (Francis et al, 2003), we chose to examine F2 littermates from F1 heterozygous breeding pairs.

Mice were kept in groups of five to six in plastic cages $(30 \times 20 \times 16 \mathrm{~cm})$ on corn dust bedding. They were housed at $24^{\circ} \mathrm{C}$ with a $12 / 12$-h light/dark cycle with ad libitum access to food and water. All experiments were conducted on mice between 6 and 11 weeks of age. The analyses of baseline startle, habituation, and PPI were performed with the same population of GAD65 wild-type (WT, $n=12 ; 7$ males, 5 females), heterozygous (HET, $n=13 ; 5$ males, 8 females), and homozygous knockout (KO, $n=10 ; 6$ males, 4 females) mice. Both females and males were included to assess possible sex differences. Since no PPI differences were observed between WT and HET mice, the examination of clozapine effects on PPI were evaluated on GAD65 WT $(n=7)$ and $\mathrm{KO}(n=7)$ mice only.

Mice were tested in a manner randomized for genotype. The genotypes of the mice were unknown to the experimenter until all tests had been completed. The experiments were approved by our Institutional Protocol Approval Committee and were in accordance with Yerkes Primate Research Center Regulations.

\section{Genotype Determination}

In situ hybridization was performed to qualitatively confirm differential expression of GAD65 in WT and KO brains (see Figure 1a). GAD65 mRNA was detected using a ${ }^{35}$ S-labeled antisense probe as follows: mice were killed by chloral hydrate overdose, perfused intracardially with $4 \%$ paraformaldehyde in phosphate-buffered saline (PBS). Brains were fixed overnight, rinsed with $\mathrm{PBS}$ and allowed to equilibrate at $4{ }^{\circ} \mathrm{C}$ in $20 \%$ sucrose/PBS, then were rapidly frozen in dry ice and stored at $-80^{\circ} \mathrm{C}$. Brains were sectioned at $16 \mu \mathrm{m}$ thickness on a Leica Cryostat (Nussloch, Germany) at $-20^{\circ} \mathrm{C}$ onto gelatin-coated slides. In situ hybridization was performed as previously described (Ressler et al, 2002). ${ }^{35} \mathrm{~S}$-UTP $(1250 \mathrm{Ci} / \mathrm{mmol}, 12.5 \mathrm{mCi} / \mathrm{ml}, \mathrm{NEN}$, Boston, MA)labeled riboprobes were prepared from linearized clones a

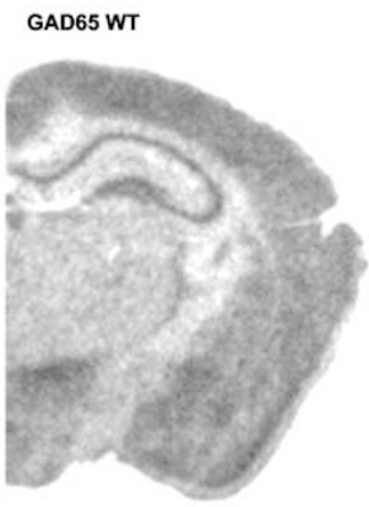

GAD65 KO
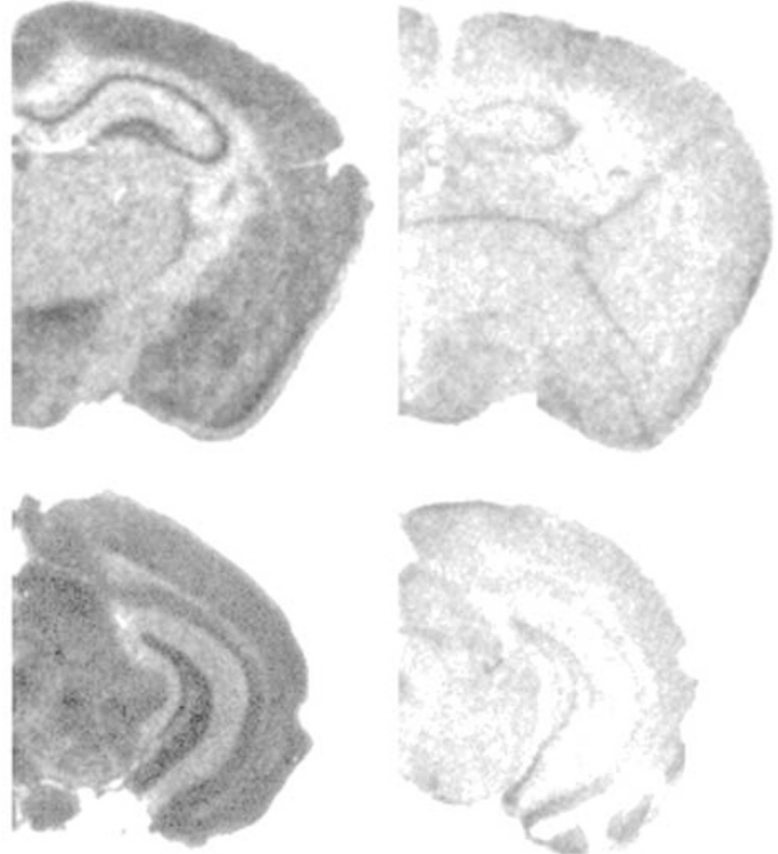

b

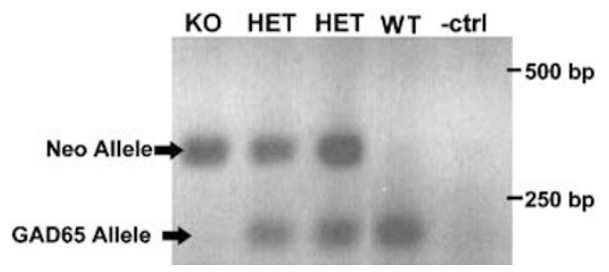

Figure I (a) Representative photomicrographs of GAD65 WT and KO brains in which in situ hybridization was performed using a ${ }^{35} \mathrm{~S}$-labeled antisense probe for GAD65 mRNA. (b) Examples of PCR analysis of GAD65 transcripts from tail DNA digests.

using T7 or T3 polymerase at high specific activity by only using radioactive UTP in the polymerase reaction, with approximately $20 \%$ incorporation. Following preparation of full-length antisense RNA strands, the RNA was base hydrolyzed to average lengths of $50-100 \mathrm{bp}$ and isolated using a sephadex gravity flow column. Hybridizations were performed under parafilm at $52^{\circ} \mathrm{C}$ overnight. Slides were then stringently washed, dried and placed against Kodak (Rochester, NY) MR autorad. film for 1-5 days.

Mice were genotyped by polymerase chain reaction (PCR) using the following customized primers: GAD65A, GTCTAGCAGAACCCATGGCG; GAD65B, GTTTCCTGTT GCAGATGTCAAAG; NeoA, GATTGCACGCAGGTTCTCC; and NeoB, CTTTCTCGGCAGGAGCMG (Sigma Chemical, St Louis, MO). PCR was performed using Taq DNA polymerase (Sigma). In all, 40 cycles were run at $95^{\circ} \mathrm{C}$ for $30 \mathrm{~s}, 58^{\circ} \mathrm{C}$ for $30 \mathrm{~s}$, and $72^{\circ} \mathrm{C}$ for $1 \mathrm{~min}$. After PCR, the samples were run on $2 \%$ agarose gels and were visualized by ethidium bromide and UV-transillumination. GAD65A and B primers generated a $189 \mathrm{bp}$ band if the WT allele was present, and $\mathrm{NeoA}$ and $\mathrm{B}$ primers generated a $300 \mathrm{bp}$ band if the KO 
allele was present (see Figure 1b). Band analysis was accomplished using Eagle Eye software (Stratgene).

\section{Drug}

Clozapine was obtained from RBI/Sigma (Sigma Chemical, St Louis, MO). The drug was dissolved in a vehicle solution consisting of saline with $10 \%$ DMSO. Mice were injected intraperitonally with $200 \mu \mathrm{l}$ of drug (Cloz) or vehicle (Veh) $30 \mathrm{~min}$ before behavioral testing. The drug concentration of clozapine $(6 \mathrm{mg} / \mathrm{kg})$ was chosen on the basis of previous studies of doses required to obtain behavioral effects in mice and rats (eg Dirks et al, 2003; Zhang et al, 1999).

\section{Apparatus}

Startle reflexes were measured in eight identical startle response systems (SR-LAB, SDI, San Diego, CA). Each system consisted of a nonrestrictive Plexiglas cylinder, $5.5 \mathrm{~cm}$ in diameter and $13 \mathrm{~cm}$ long, mounted on a Plexiglas platform located in a ventilated, sound-attenuated chamber. Cylinder movements were detected by a piezoelectric accelerometer mounted under each platform and were digitized and stored by an interfacing computer assembly. Movements were sampled each millisecond (ms) and startle amplitude was defined as the peak accelerometer voltage that occurred during the first $100 \mathrm{~ms}$ after the onset of the startle stimulus. Response sensitivities were calibrated (SR-LAB Startle Calibration System) to be nearly identical in each of the eight startle cylinders. Startle, prepulse, and background stimuli were presented through a highfrequency speaker located $15 \mathrm{~cm}$ above the startle chambers. Stimuli intensities were verified with the microphone of a sound level meter (Radio Shack, \#33-2055) placed inside the cylinder. Stimuli presentation and data acquisition were controlled by an IBM PC-compatible computer using SRLab software.

\section{Procedure}

Acclimation. For 3 consecutive days, each mouse was placed in the cylinder for approximately $15 \mathrm{~min}$ during which time no stimuli were presented. The purpose of this acclimation procedure was to familiarize the mice to handling and the startle apparatus.

Startle. The following day mice were placed in the cylinder and after 5 min were given 10 startle stimuli at each of four different startle stimulus intensities $(90,100,110,120 \mathrm{~dB})$ with an interstimulus interval (ISI) of $30 \mathrm{~s}$. All startle stimuli were presented in a pseudorandom sequence with the constraint that each stimulus intensity occur only once in each consecutive four-trial block. A total of 10 trial blocks were presented.

PPI test sessions. Each PPI test session consisted of five different trial types. Startle stimuli $(115 \mathrm{~dB}, 50 \mathrm{~ms})$ were presented alone or were preceded by noise prepulses $(20 \mathrm{~ms})$ of $2,4,8,10$, or $12 \mathrm{~dB}$ above a $63 \mathrm{~dB}$ white noise background (ie $65,67,71,73$, or $75 \mathrm{~dB}$ ) with a fixed interval $(100 \mathrm{~ms})$ between onsets of the prepulse and startle stimuli. The session began with a 5-min acclimation period followed by the five different trial types presented in random order nine times for a total of 45 trials. Intertrial intervals ranged from 20 to $40 \mathrm{~s}$. Startle and PPI intensities were selected on the basis of past studies examining PPI in mice (Dirks et al, 2003; Wang et al, 2003).

The effect of clozapine treatment was evaluated using a random crossover experimental design. On PPI Test Session 1, approximately one-half of GAD65 WT and KO mice were given clozapine pretreatment $30 \mathrm{~min}$ before testing; the remaining mice were given vehicle pretreatment. PPI Test Session 2 was conducted following a 3-day drug washout period to limit pretreatment crossover effects. On this session, drug pretreatment for each mouse was reversed.

\section{Statistical Analysis and Data Reduction}

The mean startle amplitudes were calculated for each mouse by computing the average startle response at each of four different startle stimulus intensities $(90,100,110,120 \mathrm{~dB})$. These responses were analyzed with a repeated measures $3 \times 2 \times 4$ ANOVA consisting of two between-subjects main factors of Genotype (WT, HET, KO) and Sex (male, female) and of a repeated measures factor of the Stimulus Intensity $(90,100,110,120 \mathrm{~dB})$.

Startle Habituation was analyzed by first computing the mean startle amplitude for each of the 10 trial blocks. Each block consisted of an average of four different startle stimuli $(90,100,110,120 \mathrm{~dB})$. Habituation was evaluated with a $3 \times 2 \times 10$ ANOVA, with two between-subjects main factors of Genotype (WT, HET, KO) and Sex (Male, Female) and a repeated measures factor of Block (1-10). The effect of Block at each level of Genotype was subsequently examined with a single repeated measure ANOVA to obtain trend analysis and planned block contrasts. The level of significance was set at $p=0.05$.

The mean startle amplitudes for the startle-alone trials and each of the five prepulse + startle trials were calculated for each mouse by averaging the startle amplitude of each trial type. Each mean prepulse + startle amplitude score was converted to a percent PPI. The percent PPI was obtained as follows; Percent PPI $=100 \times($ mean startle-alone amplitude-mean prepulse + startle amplitude)/(mean startle-alone amplitude). To examine the effects of Genotype on PPI, results were analyzed by means of repeated measures $3 \times 2 \times 5$ ANOVA with Prepulse Intensity $(2,4,8,10$ or $12 \mathrm{~dB}$ ) as within-subject factor and Genotype (WT, HET, $\mathrm{KO}$ ) and Sex (Male, Female) as the between-subject factors. To more closely examine differences among genotype, the overall analysis was followed by subsequent one-way ANOVAs at each of the prepulse intensities. In the case of a significant main effect, contrasts comparing KO to HET and WT were performed.

Consistent with previous findings (Swerdlow et al, 2003; Willott et al, 2003), the examination of Genotype on PPI revealed no significant male $v s$ female differences. Thus, for ease of presentation, subsequent analyses of the effects of drugs on PPI were collapsed across sexes. The effect of clozapine treatment was evaluated using a random crossover experimental design. The experiment was analyzed by means of repeated measures ANOVA with Pretreatment (Cloz, Veh) and Prepulse Intensity $(2,4,8,10$ or $12 \mathrm{~dB})$ as within-subject factors and Genotype (WT, HET, KO) as a 
between-subject factor. Significant main effects or interactions were subsequently analyzed with appropriate pairedsample $t$-tests. The level of significance was set at $p=0.05$.

\section{RESULTS}

\section{Baseline Startle}

Figure 2a shows the mean startle amplitude scores at each of four different startle stimulus intensities for GAD65 WT, $\mathrm{HET}$, and $\mathrm{KO}$ mice. In general, with increasing stimulus intensity all groups of mice showed a corresponding increase in startle response. No differences were observed among genotype; however, male mice displayed a greater startle response at higher intensities when compared to females (see Figure $2 \mathrm{~b}$ ). These observations were supported by the three-way ANOVA (Genotype $\times \operatorname{Sex} \times$ Stimulus Intensity). This analysis yielded a reliable main effect of Stimulus Intensity, $F(3,87)=399.04, p<0.01$, but no main effect of Sex, $F(1,29)=0.90, p>0.05$, or Genotype, $F(2,29)=0.55, p>0.05$. There was, however, a significant Stimulus Intensity $\times$ Sex interaction, $F(3,85)=7.05$, $p<0.01$. Other interactions involving the between- and within-subject factors were not significant. In determining the source of the two-way interaction, pairwise $t$-tests at
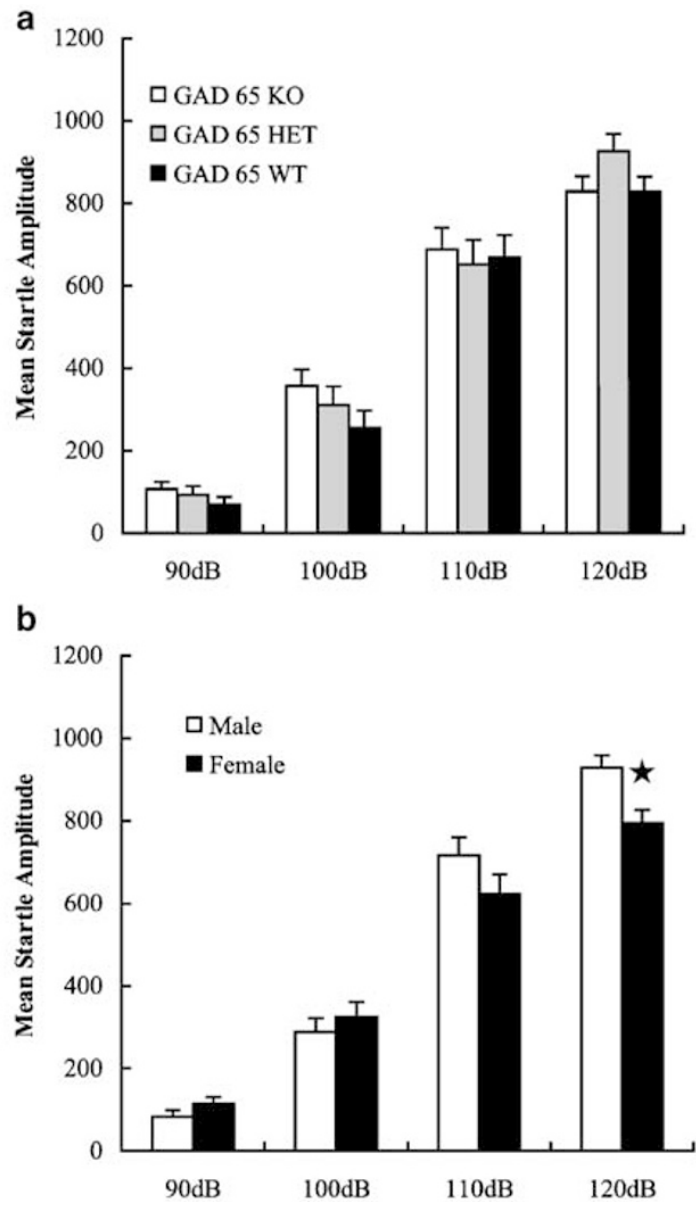

Figure 2 Mean startle amplitudes at each of four different startle stimulus intensities $(90,100,110,120 \mathrm{~dB})$. (a) Overall means for GAD65 WT, HET, and KO mice. (b) Overall means for GAD65 male and female mice irrespective of genotype. Values are means + SEM. * p's $<0.05$. each level of stimulus intensity revealed that male mice displayed a higher startle response at $120 \mathrm{db}, t(33)=3.02$, $p<0.01$. Nevertheless, both males and females showed significant increases in startle response at each subsequent stimulus intensity ( $p$ 's $<0.01)$.

\section{Habituation}

As seen in Figure 3, significant habituation was observed at all levels of genotype, and no significant differences were observed among GAD65 WT, HET, and KO mice. In support of these observations, the three-way ANOVA (Genotype $\times$ Sex $\times$ Block) yielded a reliable main effect of Block, $F(9,261)=5.65, p<0.01$, indicating a reduction of mean startle response across blocks. The main effects of Sex and Genotype were nonsignificant ( $p$ 's $>0.05)$. Withinsubject and between-subject interactions were likewise nonsignificant, $(p$ 's $>0.05)$. The effect of block at each level of genotype revealed a reliable effect for WT, HET, and KO groups $(p$ 's $<0.05)$. Each group displayed a significant linear trend, $p$ 's $<0.01$, and a significant reduction in mean startle amplitude by Block 10 ( $p$ 's $<0.03)$. Thus, a closer examination of habituation confirmed similarities in habituation among genotype groups.

\section{PPI}

In contrast to baseline startle and habituation analyses, which revealed no differences among genotype groups, the analysis of PPI indicated that GAD65 KO mice showed a robust PPI deficit (Figure 4). This finding was supported by the three-way ANOVA (Genotype $\times \operatorname{Sex} \times$ Prepulse Intensity) which yielded a reliable main effect of Prepulse Intensity, $F(1,29)=88.44, p<0.01$, and more important, a significant main effect of Genotype, $F(2,29)=9.19, p<0.01$. All remaining main effects and interactions were nonsignificant $(p$ 's $>0.05)$. The results of multiple comparisons found that GAD65 KO mice displayed significantly less PPI than WT and HET mice $(p$ 's $<0.02)$. No significant

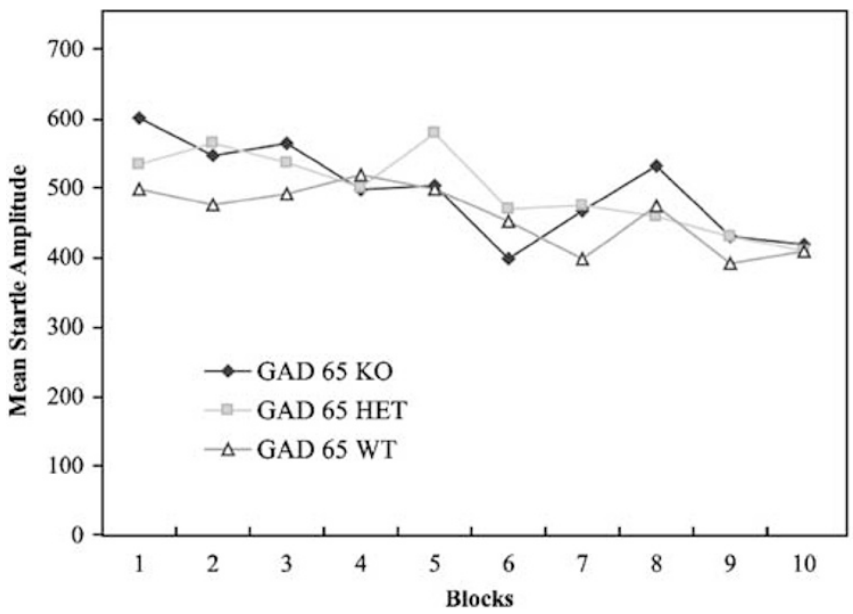

Figure 3 Mean startle amplitudes at each of 10 trial blocks for GAD65 WT, HET, and KO mice. During testing, startle stimuli were presented in a pseudorandom order with the constraint that stimulus intensity occur only once in each consecutive four-trial block. Each block consisted of the average of four different startle stimuli $(90,100,110,120 \mathrm{~dB})$. 

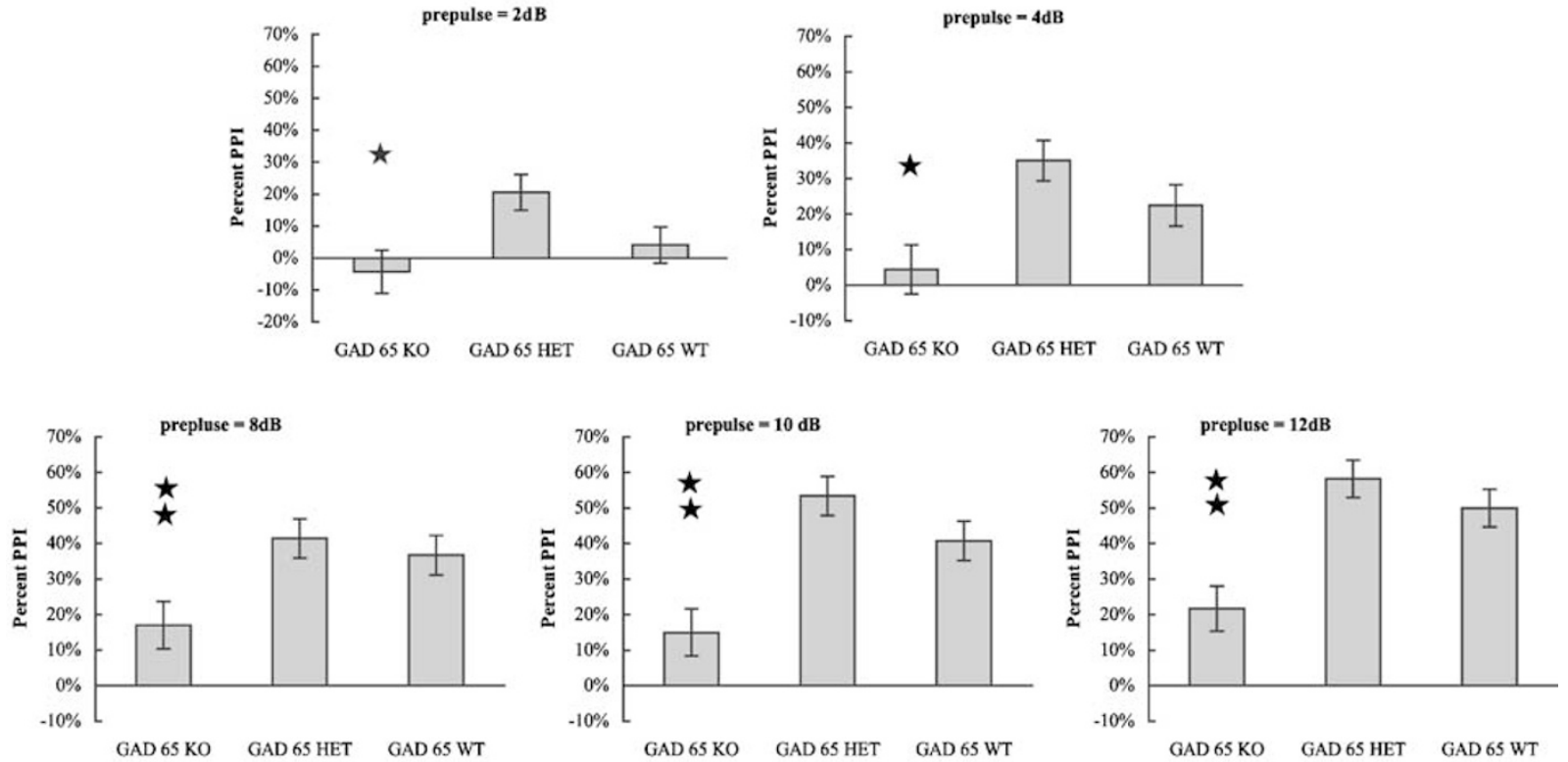

Figure 4 Percent PPI for GAD65 WT, HET, and KO mice. Each graph depicts percent PPI values at one of five different prepulse intensities (2, 4, 8, I0, $12 \mathrm{~dB}$ ). Values are means \pm SEM. *KO vs HET, $p<0.05$; **KO vs HET and KO vs WT, p's $<0.05$

differences were observed between WT and HET mice $(p$ 's $>0.05)$.

One-way ANOVAs indicated significant between-group effects at each Prepulse Intensity $(2,4,8,10$ and $12 \mathrm{~dB})$, $F$ 's $(2,32)>3.98, p$ 's $<0.03$. Planned comparisons revealed that GAD65 KO mice displayed less PPI than both WT and HET at prepulse intensities of 8,10 , and $12 \mathrm{~dB}\left(p^{\prime}\right.$ 's $\left.<0.04\right)$. At intensities of 2 and $4 \mathrm{~dB}, \mathrm{KO}$ mice exhibited less PPI than HET mice $(p$ 's $<0.04)$. Finally, in accordance with the baseline startle response results above, GAD65 WT, HET, and $\mathrm{KO}$ mice showed no differences on mean startle amplitudes on startle-alone trials (ie trials without a prepulse), $F(2,32)=0.17, p>0.05$.

\section{Clozapine}

Since no overall differences were observed between GAD65 WT and HET on PPI, the examination of clozapine effects on PPI were evaluated using GAD65 WT and KO mice only. As seen in Figure 5, clozapine $(6 \mathrm{mg} / \mathrm{kg})$ pretreatment 30 min before testing significantly increased PPI in GAD65 KO mice but had little effect on WT mice. These findings were supported by the three-way ANOVA (Genotype $\times$ Pretreatment $\times$ Prepulse Intensity). This analysis yielded reliable main effects of Genotype, $F(1,10)=15.14, p<0.01$, Pretreatment, $F(1,10)=14.90, p<0.01$, and Prepulse Intensity, $F(4,40)=15.22, p<0.01$. Most important was the significant Genotype $\times$ Pretreatment interaction, $F(1,10)=$ $7.34, p<0.03$, suggesting a differential effect of pretreatment on levels of genotype. Follow-up paired-sample $t$-tests indicated that GAD65 KO mice displayed greater PPI after pretreatment of clozapine when compared to vehicle, $t(6)=5.60, p<0.01$. In contrast, WT mice showed no significant pretreatment differences $t(6)=0.89, p>0.05$. For GAD65 KO mice, individual analyses at each of the prepulse intensities indicated that clozapine significantly increased PPI at 4,8 , and $12 \mathrm{~dB}\left(p^{\prime}\right.$ s $\left.<0.04\right)$.
An analysis of the effect of pretreatment on mean startle amplitudes of startle-alone trials (ie trials without a prepulse) indicated that clozapine significantly reduced mean startle amplitudes, $F(1,12)=12.78, p<0.01$ (Veh: $\mathrm{M}=865, \mathrm{SEM}=67$; Cloz: $\mathrm{M}=702$, SEM =69). The Genotype by Pretreatment interaction was nonsignificant, $F(1,12)=1.30, p>0.05$. This latter finding is consistent with a number of studies showing clozapine's inhibitory effect on baseline startle amplitudes (eg Dirks et al, 2003).

\section{DISCUSSION}

The current study demonstrated that $\mathrm{KO}$ mice lacking the $65-\mathrm{kDa}$ isoform of glutamic acid decarboxylase (GAD65) showed a robust PPI deficit. This finding was observed when GAD65 KO mice were compared to HET and/or WT mice in each of two different cohorts of animals. Treatment with the atypical antipsychotic clozapine significantly improved PPI deficits in the KO mice, while it had no effect in WT mice. Clozapine also reduced baseline startle amplitudes in both $\mathrm{KO}$ and WT mice. However, as has been shown in previous studies (eg Dirks et al, 2003), the efficacy of clozapine in alleviating PPI deficits could not be explained by changes in baseline startle. The above results suggest that the integrity of GABAergic systems, and in particular GAD65, is necessary for the normal expression of PPI.

Although GAD65 KO mice displayed a robust PPI deficit, the current study did not find a genotype difference in startle habituation. Likewise, no genotype effect was observed in baseline startle amplitudes. The current study did, however, find a sex difference in startle amplitude; namely, male mice displayed higher startle responses than females. This effect was driven primarily by a large sex difference at high startle intensities and is consistent with past studies demonstrating that male rats and mice display higher startle responses than females (Faraday and 


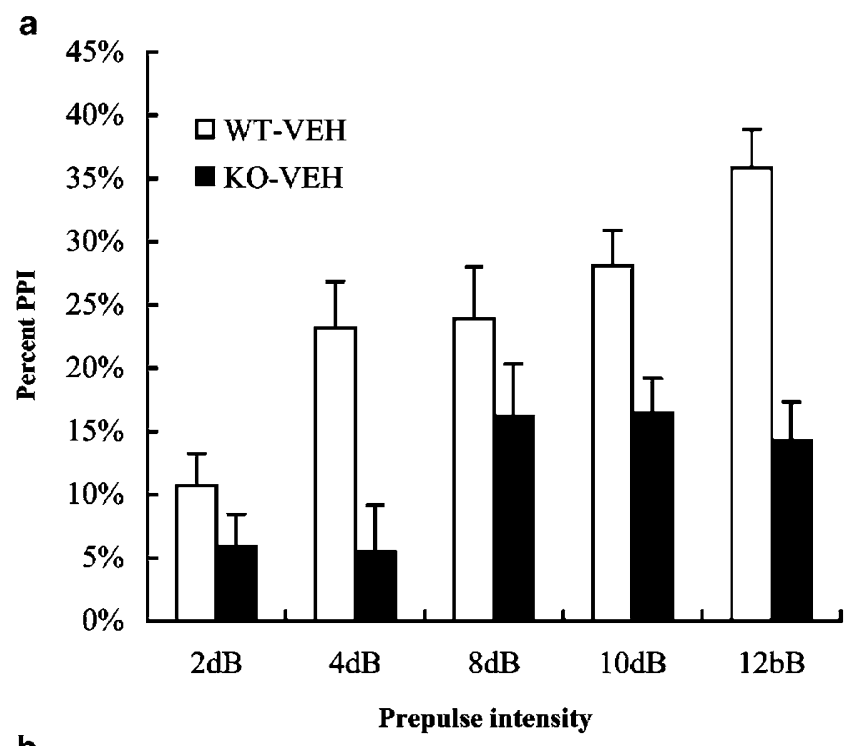

b

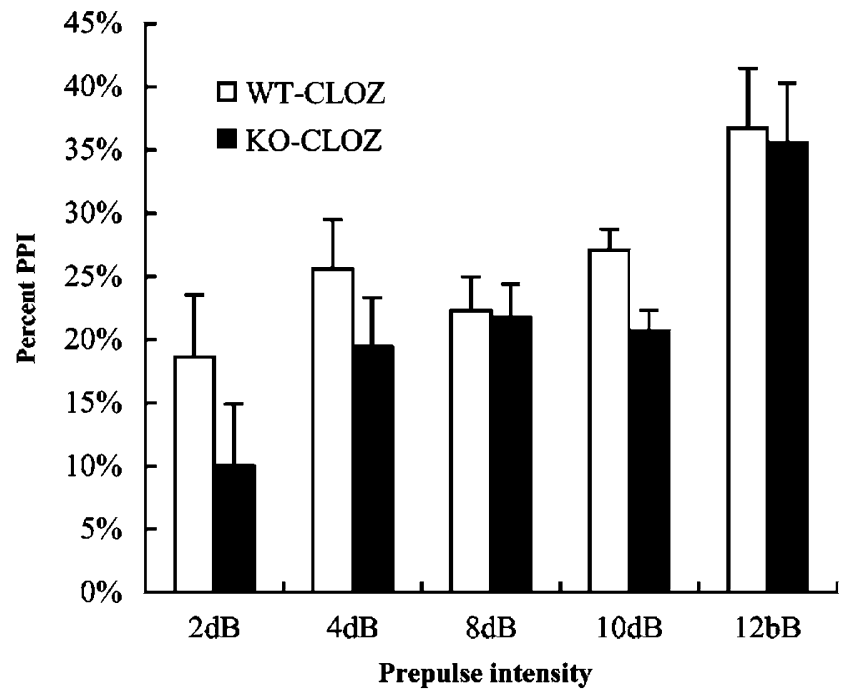

Figure 5 Effects of clozapine on prepulse inhibition of the acoustic startle response in GAD65 WT and GAD65 KO mice. Graphs depict percent PPI values at five different prepulse intensities $(2,4,8,10,12 \mathrm{~dB})$. GAD65 WT and KO mice were given intraperitoneal injections of either (a) vehicle (VEH) or (b) clozapine (CLOZ) 30 min before behavioral testing using a random crossover experimental design. After CLOZ pretreatment, GAD65 $\mathrm{KO}$ displayed significant increased PPI at 4,8 , and $12 \mathrm{~dB}$ (p's<0.05). Values are means + SEM.

Grunberg, 2000; Lehmann et al, 1999; Logue et al, 1997). Despite this finding, no differences were detected between males and females on PPI.

Like PPI, deficits in startle habituation are also seen in schizophrenic patients (Bolino et al, 1992; Braff et al, 1978; Braff et al, 1992; Ludewig et al, 2003). However, short-term startle habituation is believed to occur within the primary startle pathway (Davis, 1984; Koch and Schnitzler, 1997; Leaton et al, 1985; Weber et al, 2002). In contrast, neuroanatomical and pharmacological studies indicate that PPI is mediated by brain circuitry that includes the hippocampus, medial prefrontal cortex, nucleus accumbens, amygdala, striatum, and pallidum. This modulatory circuit converges with the primary startle pathway at the level of the nucleus reticularis pontis caudalis (eg Swerdlow et al, 2001). Our results are consistent with the view that PPI and habituation are two independent measures of startle plasticity, which are supported by separate but interacting neural mechanisms. Furthermore, the above finding supports current views that percent PPI is independent of the magnitude of the startle response in mice and rats (eg Paylor and Crawley, 1997).

No differences in PPI were observed between GAD65 WT and HET mice. This finding is consistent with past data that indicate that the behaviors of GAD65 HET mice are more similar to WT than to KO mice (Stork et al, 2000; Stork et al, 2003). During postnatal development, both GAD65 WT and HET mice display a GAD65-dependent increase of GABA levels (Stork et al, 2000). As adults, the brain GABA levels are similar between GAD65 WT and HET mice; however, the normal developmental increases in GABA levels are delayed by about 2 months in HET mice. Thus, the lack of difference between WT and HET mice may reflect the fact that they were tested at about 2 month of age. At this age, GABA levels in HET animals may be sufficient for normal PPI. Future studies could examine whether PPI differences exist between WT and HET mice of younger age.

The precise physiological mechanisms by which acute clozapine was able to reverse the PPI deficit in GAD KO mice is unknown. Clozapine is known to have a high affinity for dopamine D2 receptors and the D2 antagonist effects are believed to contribute to the clinical actions of many atypical antipsychotics such as clozapine (Remington, 2003). Likewise, the ability of atypical antipsychotics to reduce drug-induced PPI deficits in rats is generally believed to be directly related to their affinities for D2 dopamine receptors (Swerdlow et al, 1994). At present, it is unknown whether GAD65 KO mice show abnormalities in dopaminergic regulation. However, in view of the anatomical and functional connections between dopamine and GABA systems, it seems likely that GABAergic dysfunction would directly influence dopamine neurotransmission in GAD65 KO mice. For example, both the active and spontaneous release of dopamine is known to be controlled by GABAergic neurons found in the VTA. These cells regulate the activity of DA output neurons by tonic inhibition of neural activity through the $\mathrm{GABA}_{\mathrm{A}}$ receptor (Westerink et al, 1996). The inhibition of dopamine transmission is also under the control of descending GABAergic projections from the nucleus accumbens to subpallidal regions, including the ventral pallidum (Koch and Schnitzler, 1997). Experiments using in vivo injections of GAD65 isoform-specific antisense oligonucleotides into nucleus accumbens have further demonstrated the requirement of GAD65 in attentional processes (Miner and Sarter, 1999). Thus, a reduction of GAD65-dependent GABA activity would be expected to lead to hyperactivity of midbrain and forebrain dopamine neurons.

In addition to dopamine D2 receptors, clozapine also has a high affinity for D1 and serotonin 5-HT2 receptors, which could have mediated the reversal of PPI deficits in GAD65 KOs. In fact, there appears to be synergistic interaction among D1, D2, and 5-HT2 receptors which may account for its enhanced clinical benefits when compared with conventional 'typical' antipsychotics like haloperidol (Remington, 2003; also see Wan et al, 1996). Interestingly, recent results 
suggest D1 receptors may play a more prominent role in the modulation of PPI in mice (Ralph-Williams et al, 2003). Current studies are underway to examine whether typical antipsychotics or antagonists selective for D1, D2, or 5-HT2 also alleviate PPI deficits in GAD65 KOs.

Our finding that acute administration of clozapine was effective in restoring PPI deficits in mice lacking GAD65 is in line with past studies in rats which have demonstrated that the acute effects of clozapine-like antipsychotics are successful in attenuating PPI deficits induced by administration of dopamine agonists (eg Rasmussen et al, 1997; Swerdlow and Geyer, 1993), serotonin agonists (Varty and Higgins, 1995), and NMDA antagonists (Bakshi and Geyer, 1995; Yamada et al, 1999; Zhang et al, 1999). Acute administration of atypical antipsychotics can also restore PPI deficits seen in neurodevelopmental models of schizophrenia such as neonatal ventral hippocampal lesions (Le Pen and Moreau, 2002), maternal separation (Ellenbroek et al, 1998), and social isolation (Varty and Higgins, 1995; also see, Feifel et al, 2004). Likewise, recent findings in mice have also illustrated the effectiveness of acute administration of atypical antipsychotics in alleviating various mouse models of PPI deficits (Brody et al, 2004; Dirks et al, 2003; Shi et al, 2003; also see, Russig et al, 2004). For example, using C57BL/6J mice, Brody et al (2004) recently demonstrated that acute administration of clozapine and the typical antipsychotic raclopride were effective in reversing both amphetamine and ketamine-induced PPI deficits. Thus, acute clozapine administration is effective in normalizing both pharmacological and nonpharmacological models of PPI deficits.

As a model of gating deficits in schizophrenia, the effectiveness of pharmacological compounds in alleviating PPI deficits in rats is widely used to screen for new antipsychotic medications (Braff et al, 2001; Geyer et al, 2001; Swerdlow and Geyer, 1993). Indeed, antipsychotic medicines may decrease PPI deficits when administered to patients with schizophrenia (Braff et al, 2001). Given the fact that chronic administration is normally associated with the clinical properties of antipsychotic drugs, the acute behavioral effects in rodents may not fully mimic the clinical properties of these drugs (Geyer et al, 2001; Martinez et al, 2000). Interestingly, a number of studies which have directly compared acute $v s$ chronic treatment with both typical and atypical antipsychotics have demonstrated that acute may be more effective than chronic administration at reducing PPI deficits induced by pharmacological or environmental manipulations (Andersen and Pouzet, 2001). Thus, in rodents, chronic administration of antipsychotics may induce long-term changes that counteract the PPI-enhancing effects of clozapine (Zarate et al, 2004), and in some cases may not be as useful in assessing clinical properties.

GABA is the major inhibitory neurotransmitter in the mammalian central nervous system and is synthesized from GAD in GABAergic neurons. Immunohistochemical and in situ hybridization studies indicate that almost all GABAergic neurons in the brain coexpress two GAD isoforms. GABA derived from GAD67 is believed to play an essential role in early neurogenesis. GAD67 KO mice show a marked reduction of GABA levels throughout the brain and die shortly after birth due to the development of a cleft palate (Asada et al, 1997). The contribution of GAD65 to GABA synthesis appears to be regulated in a regionspecific manner. Previous studies have shown no deficit of GABA content in the hippocampus, cerebellum, or cerebral cortex of GAD65 KO mice (Asada et al, 1996; Kash et al, 1997). In these brain areas, basal synaptic transmission appears to be essentially normal in GAD65 $\mathrm{KO}$ mice compared with the WT mice. However, during sustained stimulation a marked defect in transmitter release is detected. Similarly, in the visual cortex, the steady-state response to prolonged stimulation is reduced in $\mathrm{KO}$ mice (Choi et al, 2002). These findings suggest that in the hippocampus and cortex, GAD65 may be important only at times of increased GABAergic transmission.

In contrast to the hippocampus, basal levels of GABA in the amygdala, hypothalamus, and parietal cortex are significantly lower in GAD65 KO mice compared with the WT and HET mice. In these brain areas, WT and HET animals display a GAD65-dependent increase of GABA levels during the first weeks of postnatal development, which are retained throughout adult life. In contrast, GAD65 KO mice display no developmental increase (Stork et al, 2000). As a consequence, GAD65 KO mice develop sustained deficits in GABA levels which are particularly strong in the amygdala, where the distribution of GAD65 is normally quite high (Sheikh et al, 1999). The reduction in GABA levels during postnatal maturation likely results in a loss of tonic inhibition in these brain areas and is believed to be the cause of the abnormal neural activity and spontaneous seizures displayed by GAD65 $\mathrm{KO}$ mice. GAD65 KO mice also display increased anxiety-like behaviors and diminished response to benzodiazepines and barbiturates, which have likewise been attributed to reduced GABAergic neurotransmission in the amygdala (Kash et al, 1997). It is therefore conceivable that a GABA deficit in the amygdala of GAD65 KO mice may evoke neuronal hyperexcitability, which, in turn, leads to the development of abnormal sensory gating.

There exists compelling evidence that an overflow of activity from the amygdala may make a significant contribution to the pathophysiology of schizophrenia. Consistent with the dopamine hypothesis of schizophrenia, microdialysis studies have shown long-lasting increases in mesoaccumbens dopamine efflux following activation of the amygdala. These effects appear to be mediated by direct glutamatergic afferents from the amygdala to the nucleus accumbens (for a review, see Phillips et al, 2003). In addition, amygdala kindling has been found to increase the density of dopamine receptors in the nucleus accumbens (Csernansky et al, 1988) and produce significant PPI deficits in rats (Koch and Ebert, 1998). Moreover, a number of theories have proposed that an increase of excitatory activity entering the hippocampus from the amygdala via both direct and indirect pathways may significantly contribute to the pathophysiology of schizophrenia (Bast and Feldon, 2003; Bast et al, 2001; Benes and Berretta, 2000; Berretta et al, 2001). Taken together, these observations and views support the hypothesis that hyperactivation of the amygdala may be involved in the induction of neurochemical and behavioral abnormalities found in schizophrenia.

A number of research groups have investigated brains from schizophrenic patients and have reported significant 
alterations in levels of GAD activity in several brain areas. For instance, decreases in GAD67 expression have been reported in prefrontal cortex (Akbarian et al, 1995; Guidotti et al, 2000; Hashimoto et al, 2003; Volk and Lewis, 2002), temporal cortex (Impagnatiello et al, 1998), and hippocampus (Heckers et al, 2002) of schizophrenic patients. Mixed results have been reported by the few studies which have examined levels of GAD65. For example, in one postmortem study Todtenkopf and Benes (1998) found only minor overall changes in the GAD65 expression of schizophrenic patients. However, in a small number of subjects who were free from antipsychotic drugs for at least a year prior to death, profound reductions of GAD65 levels were observed (Todtenkopf and Benes, 1998). The latter finding may suggest that untreated schizophrenic patients might inherently have reduced GAD65 expression in the hippocampus, which can be upregulated with exposure to antipsychotic drugs. Consistent with this idea, chronic administration of antispychotics in rodents has been associated with an upregulation of GAD mRNAs (Lipska et al, 2003; Yu et al, 1999).

Disturbances in GABAergic systems are also seen in rats given neonatal lesions of the hippocampus (Lipska et al, 2003). As adults, these animals show reductions in GAD67 mRNA at hippocampal projection sites in the prefrontal cortex, possibly reflecting deficits in GABAergic transmission. Lesioned animals also develop PPI deficits which can be reversed by atypical but not by typical antipsychotics (Le Pen and Moreau, 2002). Given the interplay between cortical and subcortical dopaminergic systems, the reduction in prefrontal GABA activity may account for the enhanced subcortical dopamine activity and PPI deficits seen in these animals (Lipska et al, 2003).

In some respects, the neurochemical and behavioral profiles of GAD65 KO mice are reminiscent of those observed in neurodevelopmental models of schizophrenia (Lipska and Weinberger, 2000; Weinberger, 1987). Such models suggest that a combination of both genetic and environmental factors result in the disruption of normal brain development, which, in turn, leads to an increased susceptibility to schizophrenia. For example, in rodents, environmental manipulations such as long-term isolation rearing and maternal deprivation result in PPI deficits and an anxiety-like behavioral profile which can persist throughout the life of the animal (Bakshi and Geyer, 1999; Cilia et al, 2001; Finamore and Port, 2000). Also like GAD65 mutants, rodents exposed to such manipulations exhibit deficits in GABAergic function (Serra et al, 2000), increases in seizure susceptibility (Matsumoto et al, 2003), and diminished responses to anxiolytics (Ojima et al, 1997). Thus, unlike models for sensorimotor gating deficiencies that rely on acute systemic drug injection or surgical manipulations, the PPI deficits seen in GAD65 mutants may provide another alternative, noninvasive model to study the environmental and genetic factors contributing to the development of sensorimotor/PPI deficits. Furthermore, in contrast to environmental manipulations that lead to PPI impairments, the current model may also be useful for investigating environmental and pharmacological manipulations which might ameliorate the development of sensorimotor deficits caused by abnormalities in GAD65 production. For example, early postnatal handling, which both increases GABAergic function and decreases anxietylike behavior in adult rodents (Caldji et al, 2000; Caldji et al, 1998), may also have a protective effect against the development of PPI deficits in GAD65 KO mice.

\section{ACKNOWLEDGEMENTS}

This work was supported by grants from the following agencies: NARSAD, Rockefeller Brothers Fund, NIH (MH069884), and Center for Behavioral Neuroscience (NSF agreement IBN-987675).

\section{REFERENCES}

Akbarian S, Kim JJ, Potkin SG, Hagman JO, Tafazzoli A, Bunney Jr WE (1995). Gene expression for glutamic acid decarboxylase is reduced without loss of neurons in prefrontal cortex of schizophrenics. Arch Gen Psychiatry 52: 258-266.

Andersen MP, Pouzet B (2001). Effects of acute versus chronic treatment with typical or atypical antipsychotics on D-amphetamine-induced sensorimotor gating deficits in rats. Psychopharmacology (Berl) 156: 291-304.

Asada H, Kawamura Y, Maruyama K, Kume H, Ding R, Ji FY et al (1996). Mice lacking the $65 \mathrm{kDa}$ isoform of glutamic acid decarboxylase (GAD65) maintain normal levels of GAD67 and GABA in their brains but are susceptible to seizures. Biochem Biophys Res Commun 229: 891-895.

Asada H, Kawamura Y, Maruyama K, Kume H, Ding RG, Kanbara $\mathrm{N}$ et al (1997). Cleft palate and decreased brain gammaaminobutyric acid in mice lacking the $67-\mathrm{kDa}$ isoform of glutamic acid decarboxylase. Proc Natl Acad Sci USA 94: 6496-6499.

Bakshi VP, Geyer MA (1995). Antagonism of phencyclidineinduced deficits in prepulse inhibition by the putative atypical antipsychotic olanzapine. Psychopharmacology (Berl) 122: 198-201.

Bakshi VP, Geyer MA (1999). Ontogeny of isolation rearinginduced deficits in sensorimotor gating in rats. Physiol Behav 67: 385-392.

Bast T, Feldon J (2003). Hippocampal modulation of sensorimotor processes. Prog Neurobiol 70: 319-345.

Bast T, Zhang WN, Feldon J (2001). Hyperactivity, decreased startle reactivity, and disrupted prepulse inhibition following disinhibition of the rat ventral hippocampus by the GABA(A) receptor antagonist picrotoxin. Psychopharmacology (Berl) 156: 225-233.

Beasley CL, Zhang ZJ, Patten I, Reynolds GP (2002). Selective deficits in prefrontal cortical GABAergic neurons in schizophrenia defined by the presence of calcium-binding proteins. Biol Psychiatry 52: 708-715.

Benes FM, Berretta S (2000). Amygdalo-entorhinal inputs to the hippocampal formation in relation to schizophrenia. Ann NY Acad Sci 911: 293-304.

Benes FM, McSparren J, Bird ED, SanGiovanni JP, Vincent SL (1991). Deficits in small interneurons in prefrontal and cingulate cortices of schizophrenic and schizoaffective patients. Arch Gen Psychiatry 48: 996-1001.

Berretta S, Munno DW, Benes FM (2001). Amygdalar activation alters the hippocampal GABA system: 'partial' modelling for postmortem changes in schizophrenia. J Comp Neurol 431: 129-138.

Bolino F, Manna V, Di Cicco L, Di Michele V, Daneluzzo E, Rossi A et al (1992). Startle reflex habituation in functional psychoses: a controlled study. Neurosci Lett 145: 126-128. 
Braff D, Stone C, Callaway E, Geyer M, Glick I, Bali L (1978). Prestimulus effects on human startle reflex in normals and schizophrenics. Psychophysiology 15: 339-343.

Braff DL, Geyer MA, Swerdlow NR (2001). Human studies of prepulse inhibition of startle: normal subjects, patient groups, and pharmacological studies. Psychopharmacology (Berl) 156: 234-258.

Braff DL, Grillon C, Geyer MA (1992). Gating and habituation of the startle reflex in schizophrenic patients. Arch Gen Psychiatry 49: 206-215.

Brody SA, Conquet F, Geyer MA (2004). Effect of antipsychotic treatment on the prepulse inhibition deficit of mGluR5 knockout mice. Psychopharmacology (Berl) 172: 187-195.

Caldji C, Francis D, Sharma S, Plotsky PM, Meaney MJ (2000). The effects of early rearing environment on the development of GABAA and central benzodiazepine receptor levels and noveltyinduced fearfulness in the rat. Neuropsychopharmacology 22: 219-229.

Caldji C, Tannenbaum B, Sharma S, Francis D, Plotsky PM, Meaney MJ (1998). Maternal care during infancy regulates the development of neural systems mediating the expression of fearfulness in the rat. Proc Natl Acad Sci USA 95: 5335-5340.

Choi S-Y, Morales B, Lee H-K, Kirkwood A (2002). Absence of long-term depression in the visual cortex of glutamic acid decarboxylase-65 knock-out mice. J Neurosci 22: 5271-5276.

Cilia J, Reavill C, Hagan JJ, Jones DN (2001). Long-term evaluation of isolation-rearing induced prepulse inhibition deficits in rats. Psychopharmacology (Berl) 156: 327-337.

Csernansky JG, Mellentin J, Beauclair L, Lombrozo L (1988). Mesolimbic dopaminergic supersensitivity following electrical kindling of the amygdala. Biol Psychiatry 23: 285-294.

Davis M (1984). The mamalian startle response. In Eaton RC (ed) Neural Mechanisms of Startle Behavior. Plenum Publishing: New York. pp 287-351.

Dirks A, Groenink L, Westphal KG, Olivier JD, Verdouw PM, van der Gugten J et al (2003). Reversal of startle gating deficits in transgenic mice overexpressing corticotropin-releasing factor by antipsychotic drugs. Neuropsychopharmacology 28: $1790-1798$.

Ellenbroek BA, van den Kroonenberg PT, Cools AR (1998). The effects of an early stressful life event on sensorimotor gating in adult rats. Schizophr Res 30: 251-260.

Faraday MM, Grunberg NE (2000). The importance of acclimation in acoustic startle amplitude and pre-pulse inhibition testing of male and female rats ${ }^{\star} 1$. Pharmacol Biochem Behav 66: 375-381.

Feifel D, Melendez G, Shilling PD (2004). Reversal of sensorimotor gating deficits in Brattleboro rats by acute administration of clozapine and a neurotensin agonist, but not haloperidol: a potential predictive model for novel antipsychotic effects. Neuropsychopharmacology 29: 731-738.

Finamore TL, Port RL (2000). Developmental stress disrupts habituation but spares prepulse inhibition in young rats. Physiol Behav 69: 527-530.

Francis DD, Szegda K, Campbell G, Martin WD, Insel TR (2003). Epigenetic sources of behavioral differences in mice. Nat Neurosci 6: 445-446.

Geyer MA, Krebs-Thomson K, Braff DL, Swerdlow NR (2001). Pharmacological studies of prepulse inhibition models of sensorimotor gating deficits in schizophrenia: a decade in review. Psychopharmacology (Berl) 156: 117-154.

Guidotti A, Auta J, Davis JM, Di-Giorgi-Gerevini V, Dwivedi Y, Grayson DR et al (2000). Decrease in reelin and glutamic acid decarboxylase67 (GAD67) expression in schizophrenia and bipolar disorder: a postmortem brain study. Arch Gen Psychiatry 57: 1061-1069.

Hashimoto T, Volk DW, Eggan SM, Mirnics K, Pierri JN, Sun Z et al (2003). Gene expression deficits in a subclass of GABA neurons in the prefrontal cortex of subjects with schizophrenia. J Neurosci 23: 6315-6326.

Heckers S, Stone D, Walsh J, Shick J, Koul P, Benes FM (2002). Differential hippocampal expression of glutamic acid decarboxylase 65 and 67 messenger RNA in bipolar disorder and schizophrenia. Arch Gen Psychiatry 59: 521-529.

Impagnatiello F, Guidotti AR, Pesold C, Dwivedi Y, Caruncho H, Pisu MG et al (1998). A decrease of reelin expression as a putative vulnerability factor in schizophrenia. Proc Natl Acad Sci USA 95: 15718-15723.

Kalus P, Bondzio J, Federspiel A, Muller TJ, Zuschratter W (2002). Cell-type specific alterations of cortical interneurons in schizophrenic patients. Neuroreport 13: 713-717.

Kash SF, Johnson RS, Tecott LH, Noebels JL, Mayfield RD, Hanahan $\mathrm{D}$ et al (1997). Epilepsy in mice deficient in the $65-\mathrm{kDa}$ isoform of glutamic acid decarboxylase. Proc Natl Acad Sci USA 94: 14060-14065.

Koch M, Ebert U (1998). Deficient sensorimotor gating following seizures in amygdala-kindled rats. Biol Psychiatry 44: 290-297.

Koch M, Schnitzler HU (1997). The acoustic startle response in rats - circuits mediating evocation, inhibition and potentiation. Behav Brain Res 89: 35-49.

Leaton RN, Cassella JV, Borszcz GS (1985). Short-term and longterm habituation of the acoustic startle response in chronic decerebrate rats. Behav Neurosci 99: 901-912.

Lehmann J, Pryce CR, Feldon J (1999). Sex differences in the acoustic startle response and prepulse inhibition in Wistar rats. Behav Brain Res 104: 113-117.

Le Pen G, Moreau JL (2002). Disruption of prepulse inhibition of startle reflex in a neurodevelopmental model of schizophrenia: reversal by clozapine, olanzapine and risperidone but not by haloperidol. Neuropsychopharmacology 27: 1-11.

Lipska BK, Lerman DN, Khaing ZZ, Weickert CS, Weinberger DR (2003). Gene expression in dopamine and GABA systems in an animal model of schizophrenia: effects of antipsychotic drugs. Eur J Neurosci 18: 391-402.

Lipska BK, Weinberger DR (2000). To model a psychiatric disorder in animals: schizophrenia as a reality test. Neuropsychopharmacology 23: 223-239.

Logue SF, Owen EH, Rasmussen DL, Wehner JM (1997). Assessment of locomotor activity, acoustic and tactile startle, and prepulse inhibition of startle in inbred mouse strains and F1 hybrids: Implications of genetic background for single gene and quantitative trait loci analyses. Neuroscience 80: 1075-1086.

Ludewig K, Geyer MA, Vollenweider FX (2003). Deficits in prepulse inhibition and habituation in never-medicated, firstepisode schizophrenia. Biol Psychiatry 54: 121-128.

Martinez ZA, Oostwegel J, Geyer MA, Ellison GD, Swerdlow NR (2000). 'Early' and 'late' effects of sustained haloperidol on apomorphine- and phencyclidine-induced sensorimotor gating deficits. Neuropsychopharmacology 23: 517-527.

Matsumoto K, Nomura H, Murakami Y, Taki K, Takahata H, Watanabe $H$ (2003). Long-term social isolation enhances picrotoxin seizure susceptibility in mice: up-regulatory role of endogenous brain allopregnanolone in GABAergic systems. Pharmacol Biochem Behav 75: 831-835.

Miner LA, Sarter M (1999). Intra-accumbens infusions of antisense oligodeoxynucleotides to one isoform of glutamic acid decarboxylase mRNA, GAD65, but not to GAD67 mRNA, impairs sustained attention performance in the rat. Brain Res Cogn Brain Res 7: 269-283.

Ojima K, Matsumoto K, Watanabe H (1997). Flumazenil reverses the decrease in the hypnotic activity of pentobarbital by social isolation stress: are endogenous benzodiazepine receptor ligands involved? Brain Res 745: 127-133.

Paylor R, Crawley JN (1997). Inbred strain differences in prepulse inhibition of the mouse startle response. Psychopharmacology (Berl) 132: 169-180. 
Phillips AG, Ahn S, Howland JG (2003). Amygdalar control of the mesocorticolimbic dopamine system: parallel pathways to motivated behavior. Neurosci Biobehav Rev 27: 543-554.

Ralph-Williams RJ, Lehmann-Masten V, Geyer MA (2003). Dopamine D1 rather than D2 receptor agonists disrupt prepulse inhibition of startle in mice. Neuropsychopharmacology 28: $108-118$.

Rasmussen K, Gates MR, Burger JE, Czachura JF (1997). The novel atypical antipsychotic olanzapine, but not the CCK-B antagonist LY288513, blocks apomorphine-induced disruption of pre-pulse inhibition. Neurosci Lett 222: 61-64.

Remington G (2003). Understanding antipsychotic 'atypicality': a clinical and pharmacological moving target. $J$ Psychiatry Neurosci 28: 275-284.

Ressler KJ, Paschall G, Zhou XL, Davis M (2002). Regulation of synaptic plasticity genes during consolidation of fear conditioning. J Neurosci 22: 7892-7902.

Russig H, Spooren W, Durkin S, Feldon J, Yee BK (2004). Apomorphine-induced disruption of prepulse inhibition that can be normalised by systemic haloperidol is insensitive to clozapine pretreatment. Psychopharmacology (Berl) (in press).

Serra M, Pisu MG, Littera M, Papi G, Sanna E, Tuveri F et al (2000). Social isolation-induced decreases in both the abundance of neuroactive steroids and $\mathrm{GABA}(\mathrm{A})$ receptor function in rat brain. J Neurochem 75: 732-740.

Sheikh SN, Martin SB, Martin DL (1999). Regional distribution and relative amounts of glutamate decarboxylase isoforms in rat and mouse brain. Neurochem Int 35: 73-80.

Shi L, Fatemi SH, Sidwell RW, Patterson PH (2003). Maternal influenza infection causes marked behavioral and pharmacological changes in the offspring. J Neurosci 23: 297-302.

Soghomonian JJ, Martin DL (1998). Two isoforms of glutamate decarboxylase: why? Trends Pharmacol Sci 19: 500-505.

Stork O, Ji FY, Kaneko K, Stork S, Yoshinobu Y, Moriya T et al (2000). Postnatal development of a GABA deficit and disturbance of neural functions in mice lacking GAD65. Brain Res 865: $45-58$.

Stork O, Yamanaka H, Stork S, Kume N, Obata K (2003). Altered conditioned fear behavior in glutamate decarboxylase 65 null mutant mice. Genes Brain Behav 2: 65-70.

Swerdlow NR, Braff DL, Taaid N, Geyer MA (1994). Assessing the validity of an animal model of deficient sensorimotor gating in schizophrenic patients. Arch Gen Psychiatry 51: 139-154.

Swerdlow NR, Geyer MA (1993). Clozapine and haloperidol in an animal model of sensorimotor gating deficits in schizophrenia. Pharmacol Biochem Behav 44: 741-744.

Swerdlow NR, Geyer MA, Braff DL (2001). Neural circuit regulation of prepulse inhibition of startle in the rat: current knowledge and future challenges. Psychopharmacology (Berl) 156: 194-215.

Swerdlow NR, Platten A, Hanlon FM, Martinez ZA, Printz MP, Auerbach $P$ (2003). Sensitivity to sensorimotor gating-disruptive effects of apomorphine in two outbred parental rat strains and their F1 and N2 progeny. Neuropsychopharmacology 28: 226-234.

Erdlow NR, Geyer MA (1993). Clozapine and haloperidol in an animal model of sensorimotor gating deficits in schizophrenia. Pharmacology, Biochemistry and Behavior 44: 741-744.

Todtenkopf MS, Benes FM (1998). Distribution of glutamate decarboxylase65 immunoreactive puncta on pyramidal and nonpyramidal neurons in hippocampus of schizophrenic brain. Synapse 29: 323-332.

Varty GB, Higgins GA (1995). Examination of drug-induced and isolation-induced disruptions of prepulse inhibition as models to screen antipsychotic drugs. Psychopharmacology (Berl) 122: $15-26$.

Volk DW, Lewis DA (2002). Impaired prefrontal inhibition in schizophrenia: relevance for cognitive dysfunction. Physiol Behav 77: 501-505.

Wan FJ, Taaid N, Swerdlow NR (1996). Do D1/D2 interactions regulate prepulse inhibition in rats? Neuropsychopharmacology 14: $265-274$

Wang JH, Short J, Ledent C, Lawrence AJ, Buuse M (2003). Reduced startle habituation and prepulse inhibition in mice lacking the adenosine A2A receptor. Behav Brain Res 143: 201-207.

Weber M, Schnitzler HU, Schmid S (2002). Synaptic plasticity in the acoustic startle pathway: the neuronal basis for short-term habituation? Eur J Neurosci 16: 1325-1332.

Weinberger DR (1987). Implications of normal brain development for the pathogenesis of schizophrenia. Arch Gen Psychiatry 44: 660-669.

Westerink BH, Kwint HF, deVries JB (1996). The pharmacology of mesolimbic dopamine neurons: a dual-probe microdialysis study in the ventral tegmental area and nucleus accumbens of the rat brain. J Neurosci 16: 2605-2611.

Willott JF, Tanner L, O’Steen J, Johnson KR, Bogue MA, Gagnon L (2003). Acoustic startle and prepulse inhibition in 40 inbred strains of mice. Behav Neurosci 117: 716-727.

Yamada S, Harano M, Annoh N, Nakamura K, Tanaka M (1999). Involvement of serotonin $2 \mathrm{~A}$ receptors in phencyclidine-induced disruption of prepulse inhibition of the acoustic startle in rats. Biol Psychiatry 46: 832-838.

Yu J, Kallstrom L, Wiesel FA, Johnson AE (1999). Neurochemical changes in the entopeduncular nucleus and increased oral behavior in rats treated subchronically with clozapine or haloperidol. Synapse 34: 192-207.

Zarate JM, Boksa P, Baptista T, Joober R (2004). Effects of clozapine on behavioral and metabolic traits relevant for schizophrenia in two mouse strains. Psychopharmacology (Berl) 171: 162-172.

Zhang W, Pouzet B, Jongen-Relo AL, Weiner I, Feldon J (1999). Disruption of prepulse inhibition following $N$-methyl-D-aspartate infusion into the ventral hippocampus is antagonized by clozapine but not by haloperidol: a possible model for the screening of atypical antipsychotics. Neuroreport 10: 2533-2538. 